\title{
Modeling a Small Punch Testing Device
}

\author{
Samir Habibi \\ Djillali Liabes University of Sidi Bel \\ Abbes, Algeria \\ habibismr@yahoo.com
}

\author{
Abdelkader Ziadi \\ University Center of Ain Témouchent, \\ Algeria \\ ziadiaek@yahoo.com
}

\author{
Abdelkader Megueni \\ Djillali Liabes University of Sidi \\ Bel Abbes, Algeria \\ habibismr@yahoo.com
}

\begin{abstract}
A small punch test of a sample in miniature is implemented in order to estimate the ultimate load of CrMoV ductile steel. The objective of this study is to model the ultimate tensile strength and ultimate load indentation according to the geometrical parameters of the SPT using experimental data. A comparison of the model obtained with the two models (European code of practice and method of Norris and Parker) allows the design and dimensioning of an indentation device that meets the practical constraints. Implemented as a Matlab program, allows the investigation of new combinations of test variables.
\end{abstract}

Keywords-small punch test; experiments design; constraints; modeling

\section{INTRODUCTION}

The Small Punch Test (SPT) is a method considered in practice as non-destructive because of the very small size of the specimen used [1-4]. The need to test components without compromising the performance of the overall system (e.g. thermal or nuclear power plants), or the need to reduce the size of the area tested (e.g. heat affected zones, coating materials, etc.) makes the characterization through conventional mechanical tests virtually impossible [4-6]. SPT miniature tests consists of a specimen $(0.25$ to $0.50 \mathrm{~mm}$ thick and 3 to 10 $\mathrm{mm}$ in size) which is punched by a ball (usually $1 \mathrm{~mm}$ diameter to $2.5 \mathrm{~mm}$ ) [7].

Among the previous studies on the impact of different factors of SPT, the normative method of European practice [8] refers to using the ratio of the tensile stress on the maximum load of the indenter as a function of specimen thickness, diameter of the sphere indenter and the lower die of indenter. The Norris and Parker approach [9] was based on the three variables of the indentation device. Due to the lack of an experimental standard specifying the conditions and parameters chosen for the design of the necessary equipment, we mention the values of the three variables frequently cited in international publications which are $(4,2.5,0.5)[10-13],(4-5,2.5,0.5)$ [1315], $(3.8,2.54,0.5)$ [16] and $(1.5,1,0.25)$ [17-18]. The dimensions of SPT devices commonly used are shown in Table I. However certain technical constraints linking variables should be considered (e.g. the diameter of the lower die is greater than the diameter of the sphere to indent and thickness of the sample) [9].
It is thus attempted in this paper to perform an optimization of the search space by fixing a gap of $0.5^{*} \mathrm{e}-3$ between the compared models taking into account the intervals of variables and their constraint expression by a mathematical algorithm associated with a certain experiment. At first, the experimental setup is presented. Then, we proceed to develop a full factorial design on the ductile steel studied. Finally, based on a comparative study, an optimization of the geometric variables of the spherical indentation device is presented.

\section{EXPERIMENTAL PROCEDURE}

The SPT device is adapted to a universal testing machine (Instron Model 5582) equipped with a load cell of $20 \mathrm{kN}$ with calibrated tests. The test is performed to control the movement at a speed of $0.2 \mathrm{~mm} / \mathrm{min}$. A video extensometer is used to determine the load-displacement curve (F-d). The indenting tool comprises of a rigid lower die and a threaded upper die and both matrices are perforated to allow the passage of the punch, in order for the specimen to be deformed until rupture, using a ball head punch ( 1 or $2.5 \mathrm{~mm}$ in diameter, respectively for the two types of specimens required) as shown in Figure 1. Specimens routinely used in this test are of square shape $\left(10 \times 10 \mathrm{~mm}^{2}\right)$ and $0.5 \mathrm{~mm}$ thick or $3 \mathrm{~mm}$ discs $0.25 \mathrm{~mm}$ thick (specimens commonly used in transmission electron microscopy). Four nuances of ductile steel specimens of CrMoV are used in this study.

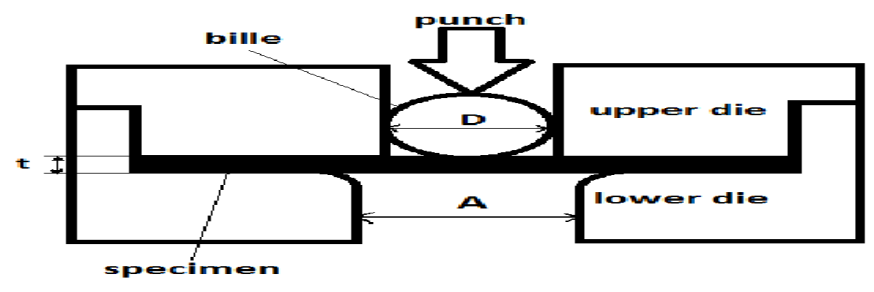

Fig. 1. Schematic illustration of the dies used in the SPT apparatus.

The probable maximum deformation is limited by the diameter of the lower die. Some researchers suggest that the dimensions of the lower hole should satisfy the following expression:

$$
A \geq D+2 t
$$


According to the literature, the design of indentation device must comply with (1) for limiting the frictional forces resulting from the contact between the specimen and the lower die.

TABLE I. COMMON GEOMETRIC DIMENSIONS OF SPT DEVICES

\begin{tabular}{|c|c|c|c|c|}
\hline & $\begin{array}{l}\text { Pastille } \\
\mathbf{D}=\mathbf{3} \mathbf{~ m m}\end{array}$ & $\begin{array}{l}\text { Square specimen } \\
\mathbf{1 0} \times \mathbf{1 0} \mathbf{~ m m}^{\mathbf{2}}\end{array}$ & $\begin{array}{l}\text { Pastille } \\
\mathbf{D =} \mathbf{~} \mathbf{~ m m}\end{array}$ & $\begin{array}{l}\text { Pastille } \\
\mathbf{D}=\mathbf{6 . 4 0} \mathbf{m m}\end{array}$ \\
\hline $\mathrm{A}=2 * \mathrm{R}$ & 1.5 & $4-5$ & 4.0 & 3.80 \\
\hline $\mathrm{D}=2 * \mathrm{p}$ & 1.0 & 2.5 & 2.5 & 2.50 \\
\hline $\mathrm{t}$ & $0.10-0.25$ & 0.5 & 0.5 & 0.5 \\
\hline
\end{tabular}

\section{MODELING OF THE DEVICE THROUGH EXPERIMENTAL} DESIGN

In order to acquire a mathematical model, the response $\sigma_{\mathrm{m}} / \mathrm{P}_{\max }$, which characterizes the behavior of the phenomenon studied according to factors $\mathrm{R}, \mathrm{p}, \mathrm{t}$ should be expressed. The high level (+1) and down (-1) of each factor are shown in Table II. Processing results are obtained using multiple linear regression and variance analysis [18] as shown in Table III. A full factorial design (order $2^{3}$ ) is performed by estimating the coefficients of the model using Yates algorithm [20]. The results are shown in Table IV.

TABLE II. CHOICE OF LEVELS OF FACTORS

\begin{tabular}{|c|c|c|c|}
\hline Factors & symbols and units & Type & Level (-1) - (+1) \\
\hline Thickness & $\mathrm{t}(\mathrm{mm})$ & Quantitatif & $0.20-0.50$ \\
\hline Lower die & $\mathrm{R}(\mathrm{mm})$ & Quantitatif & $0.75-2.00$ \\
\hline Punch & $\mathrm{p}(\mathrm{mm})$ & Quantitatif & $0.50-1.25$ \\
\hline
\end{tabular}

TABLE III. INDICATION OF RESPONSES

\begin{tabular}{|c|c|c|c|c|}
\hline tests & $\mathbf{t}$ & $\mathbf{R}$ & $\mathbf{p}$ & $\sigma_{m} / P_{\max }$ \\
\hline 1 & 0.2 & 0.75 & 0.5 & 3.25 \\
\hline 2 & 0.5 & 0.75 & 0.5 & 1.30 \\
\hline 3 & 0.2 & 2 & 0.5 & 3.96 \\
\hline 4 & 0.5 & 2 & 0.5 & 1.58 \\
\hline 5 & 0.2 & 0.75 & 1.25 & 1.08 \\
\hline 6 & 0.5 & 0.75 & 1.25 & 0.43 \\
\hline 7 & 0.2 & 2 & 1.25 & 1.32 \\
\hline 8 & 0.5 & 2 & 1.25 & 0.53 \\
\hline
\end{tabular}

TABLE IV. PRESENTATION OF DESIGN OF EXPERIMENT $2^{3}$

\begin{tabular}{|l|l|l|l|l|l|l|l|l|}
\hline tests & average & $\mathbf{X}_{\mathbf{1}}$ & $\mathbf{X}_{\mathbf{2}}$ & $\mathbf{X}_{\mathbf{3}}$ & $\mathbf{X}_{\mathbf{1}} \cdot \mathbf{X}_{\mathbf{2}}$ & $\begin{array}{l}\mathbf{X}_{\mathbf{2}} \cdot \\
\mathbf{X}_{\mathbf{3}}\end{array}$ & $\mathbf{X}_{\mathbf{1}} \cdot \mathbf{X}_{\mathbf{3}}$ & $\mathbf{Y}_{\text {test }}$ \\
\hline 1 & +1 & -1 & -1 & -1 & +1 & +1 & +1 & 3.25 \\
\hline 2 & +1 & +1 & -1 & -1 & -1 & +1 & -1 & 1.30 \\
\hline 3 & +1 & -1 & +1 & -1 & -1 & -1 & +1 & 3.96 \\
\hline 4 & +1 & +1 & +1 & -1 & +1 & -1 & -1 & 1.58 \\
\hline 5 & +1 & -1 & -1 & +1 & +1 & -1 & -1 & 1.08 \\
\hline 6 & +1 & +1 & -1 & +1 & -1 & -1 & +1 & 0.43 \\
\hline 7 & +1 & -1 & +1 & +1 & -1 & +1 & -1 & 1.32 \\
\hline 8 & +1 & +1 & +1 & +1 & +1 & +1 & +1 & 0.53 \\
\hline Divisor & 8 & 8 & 8 & 8 & & & & \\
\hline effects & $\mathrm{a}_{0}=$ & $\mathrm{a}_{1}=$ & $\mathrm{a}_{2}=$ & $\mathrm{a}_{3}=$ & $\mathrm{a}_{12}=$ & $\mathrm{a}_{23}=$ & $\mathrm{a}_{13}=$ & \\
& 1.68 & - & 0.16 & - & - & - & 0.360 & \\
& & 0.72 & & 0.84 & 0.070 & 0.082 & & \\
\hline
\end{tabular}

We then obtain the model coefficients and the average effects of factors $\mathrm{x} 1, \mathrm{x} 2, \mathrm{x} 3$ calculated.

The polynomial model is written as:

$$
y=a_{0}+\sum a_{i} \cdot x_{i}+\sum a_{i j} \cdot x_{i} \cdot x_{j}+\sum a_{i j k} \cdot x_{i} \cdot x_{j} \cdot x_{k}
$$

The treatment of the experimental design is to estimate the coefficients of the mathematical model $\mathrm{P}$ and $\mathrm{N}$ residues using the method of least squares. So the model of the studied system is expressed as follows:

$$
\frac{\sigma_{m}}{P_{\max }}=1.682-0.721 . t+0.164 . R-0.842 . p-0.070 . t \cdot R-0.082 R . p+0.360 . t . p
$$

\section{A. Validation of the Model}

The estimate of the mathematical model requires the calculation of the differences between the measured and the calculated values for each test by the following formula:

$$
e_{i}=\left(\frac{\sigma_{m}}{P_{\max }}\right)_{i}-\left(\frac{\sigma_{m}}{P_{\max }}\right)_{\text {calculé }}
$$

Residues responses are shown in Table V.

TABLE V. ESTIMATE OF RESIDUES

\begin{tabular}{|c|c|c|c|c|c|}
\hline & 1 & 2 & 3 & 4 & 5 \\
\hline 1 & $\begin{array}{c}\text { Mechanical } \\
\text { ratio }\end{array}$ & Observed & Predicted & Obs-Pred & $\begin{array}{c}\text { Conf.int } \\
( \pm)\end{array}$ \\
\hline 2 & 1 & 3.25 & 3.28625 & -0.0362499 & 1.21863 \\
\hline 3 & 2 & 1.3 & 1.26375 & 0.0362499 & 1.21863 \\
\hline 4 & 3 & 3.96 & 3.92375 & 0.0362499 & 1.21863 \\
\hline 5 & 4 & 1.58 & 1.61625 & -0.0362499 & 1.21863 \\
\hline 6 & 5 & 1.08 & 1.04375 & 0.0362504 & 1.21863 \\
\hline 7 & 6 & 0.43 & 0.46625 & -0.0362502 & 1.21863 \\
\hline 8 & 7 & 1.32 & 1.35625 & -0.0362498 & 1.21863 \\
\hline 9 & 8 & 0.53 & 0.49375 & 0.0362497 & 1.21863 \\
\hline 10 & $\mathrm{~N}=8$ & $\mathrm{Q} 2=$ & 0.940 & Cond. no. $=$ & 1.0000 \\
\hline 11 & $\mathrm{DF}=1$ & $\mathrm{R} 2=$ & 0.999 & Y-miss $=$ & 0 \\
\hline 12 & & $\mathrm{R} 2 \mathrm{Adj} .=$ & 0.993 & RSD $=$ & 0.1025 \\
\hline 13 & & & & Conf. lev. $=$ & 0.95 \\
\hline
\end{tabular}

Deviations residues explains the good dispersion of the points which means that the model obtained is acceptable.

\section{B. Significance Test of the Model Coefficients [21]}

An estimator of the common variance of the residuals is obtained. This estimator is given by:

$$
S^{2}=\frac{1}{N-p} \sum e_{i}^{2}
$$

Where $N$ is the number of experiments and $p$ is the number of coefficients in the mathematical model. For the estimation and significance of the effects of coefficients, the Student's T test was applied.

1) Descriptive Quality Model: The coefficient of determination of descriptive quality $R^{2}$ is $R^{2}=0.999$ (6) 
2) Quality of Predictive Model: the coefficient $Q^{2}$ predictive quality of the model is $Q^{2}=0.940$ (7).

Thus, the mathematical model is acceptable and allows prediction responses. Figure 2 highlights the predominance of the role of the spherical indent size factor (p) that appears larger than the others in the histogram of the contributions of different factors. Thus, we can see that the indent factor (p) and thickness (t) explain $70 \%$ of the variation. Both factors explained the $70 \%$ of the variation of the response. The contribution of the diameter of the lower die is hidden due to the small value of $07.41 \%$.

3) Graphical analysis of results: The graphical analysis of the results is shown in Figure 3. The blue zone, that is the lower part of the graph, corresponds to minor influence parameters. The slight variation of the response does not exceed $0.95 \mathrm{~mm}^{-2}$. Despite the magnitude of the radius of the indent $(1.25 \mathrm{~mm})$, the effect of the size of the matrix lower than $0.8 \mathrm{~mm}$ is not significant.

All areas (yellow, orange and red) is in the form of a "triangle" with a pointed head which is a critical point, where all the data points converge to. This means that the behavior of

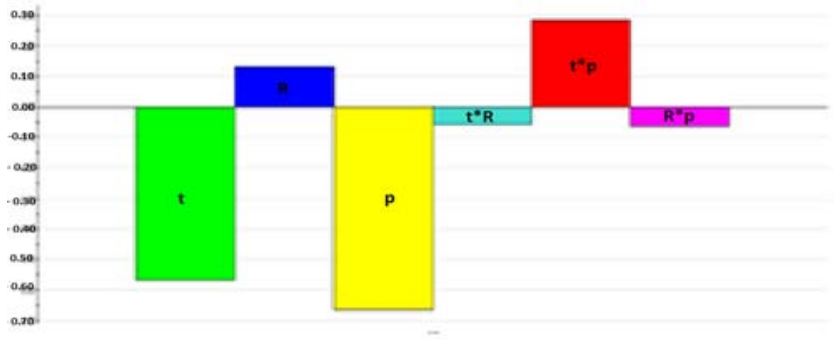

Fig. 2. Histogram of the three factors and their combined contributions.

the studied material passes another different state thereof, (a plastic deformation or rupture). We also note that the response variation in this area is even greater compared to the previous case, as we arrive to a maximum ratio of $2.75 \mathrm{~mm}^{-2}$, which comes from the interaction of two parameters, i.e. the increase of the radius of the matrix up to $2 \mathrm{~mm}$ and of the radius of the lower indent of at least $0.55 \mathrm{~mm}$. Same conclusion is drawn for the next area (greater variation, maximum ratio of 2.49 $\mathrm{mm}^{-2}$, which comes from the interaction of two parameters, i.e. the increase the radius of the matrix up to $1.6 \mathrm{~mm}$ and the decrease of the thickness of the sample of at least $0.2 \mathrm{~mm}$ ).

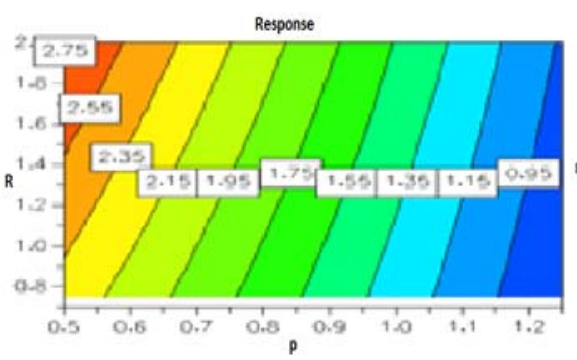

(a)

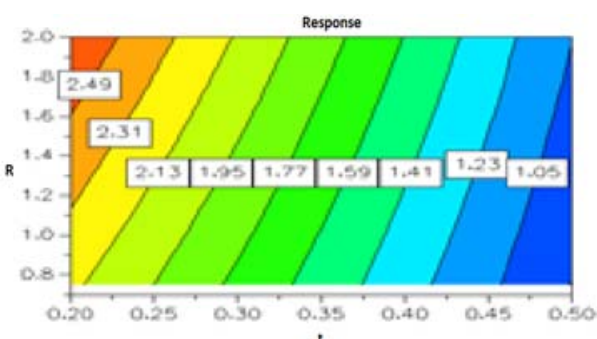

(b)

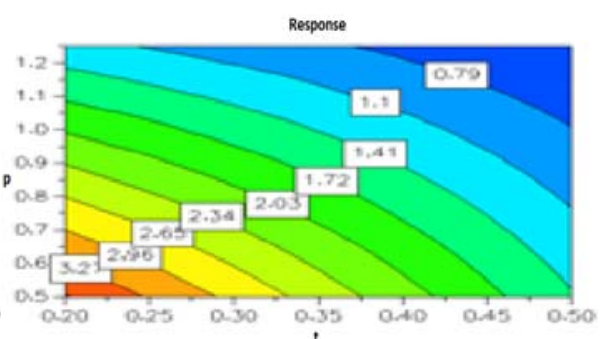

(c)

Fig. 3. Contours response (Iso-response) versus R, p, t (a) Response vs (R,p); (b) Response vs (R,t); (c) Response vs (p,t).

The analysis of the third curve shows that the simultaneous reduction of both parameters allows us to note that the variation of the response is inversely proportional, that is to say, the simultaneous decrease in the thickness and radius of the indent can generate a maximum increase in the response that reaches $3.27 \mathrm{~mm}^{-2}$ for a thickness of $0.25 \mathrm{~mm}$ and an indent radius of $0.6 \mathrm{~mm}$. It is clear that a simultaneous increase in the thickness and the indent radius results to the variation of the response being alternative and unstable. We found that, for a constant thickness, the increase in the radius of the indent causes decreased response. For an indent constant radius, increasing the thickness leads to an increase in the response. Indeed, the simultaneous increase in both parameters results in a compensation between them, one decreases and the other increases the response, which explains the curvature areas.

\section{OPTIMIZATION OF ADMISSIBLE DOMAIN}

Values $(\mathrm{R}, \mathrm{p}, \mathrm{t})$ for which the absolute value of the difference noted Res1 between the model proposed by experience (R1) and the model of the European code (R2) (and
Res2 between R1 and Norris and Parker model R3) is less than $0.5^{*} \mathrm{e}-3$ (three near significant numbers). Values are determined $(\mathrm{R}, \mathrm{p}, \mathrm{t})$ in order to acquire Res 1 and Res2 less than $0.5^{*} \mathrm{e}-3$ (three near significant numbers) and that satisfy all the constraints to determine the permissible range.

The constraint linking the combination of factors $(R, p, t)$ is:

$$
R \geq p+t
$$

The research areas of the variables $(\mathrm{R}, \mathrm{p}, \mathrm{t})$ are:

$$
\left\{\begin{array}{l}
0.75 \leq R \leq 2 \\
0.50 \leq p \leq 1.25 \\
0.20 \leq t \leq 0.50
\end{array}\right\}
$$

A program in Matlab was developed for calculating the permissible range. Variable input arguments are respectively $n$ and eps meaning the number of intervals of the variables $(\mathrm{R}, \mathrm{p}$, t) and the error imposed (eps $=0.5 * \mathrm{e}-3)$. For fixed $n$, we have 
$(n+1)^{3}$ combinations of variables recorded in the output argument. The ultimate tensile stress and ultimate load were related to sample thickness, punch diameter, and die clearance by R1, R2, R3 expressing respectively the following three models studied:

- The model built by experience level:

$R l=1.682-0.721 . t+0.164 \cdot R-0.842 . p-0.070 . t \cdot R-0.082 \cdot R \cdot p+0.360 . t . p(10)$

- The model expressed by the European code of practice

$$
R 2=3.33 \cdot R^{-0.2} \cdot r^{1.2} \cdot t
$$

where Ksp: factor dimensional correlation with $\mathrm{K}_{\mathrm{sp}}=1[2,10]$.

- The model expressed by Norris and Š.D. J.D.Parker

$$
R 3=\frac{1}{t .(3.22 D-0.9 A+1.8 t+0.56)}
$$

\section{RESULTS AND DISCUSSION}

The calculation program gave the numerical results shown in Tables VI and VII and the corresponding curves (Figures 4 and 5).

The variation curves (Figures: $4(a, b, c)$ ) factors $(R, p, t)$ depending on $n$ intervals $(n>=40)$ define the research areas of the three variables as follows:

$$
\left\{\begin{array}{l}
1.216 \leq R \leq 2.00 \\
0.716 \leq p \leq 1.25 \\
0.422 \leq t \leq 0.50
\end{array}\right\}
$$

Similarly, the variation curves (Figures: $5(\mathrm{a}, \mathrm{b}, \mathrm{c}))$ delimit spaces more reduced following research:

$$
\left\{\begin{array}{l}
1.158 \leq R \leq 2.00 \\
0.736 \leq p \leq 1.25 \\
0.297 \leq t \leq 0.50
\end{array}\right\}
$$

The results obtained by Matlab show the convergence of the curves (Figures 4 and 5) for $n=35$. The results of the models studied coincides with the third significant numeral.
For practical experimental considerations, we propose a clearance die between 0.025 and 0.25 .

TABLE VI. COMPARISON BETWEEN DESIGN EXPERIMENTS AND EUROPEAN CODE OF PRACTICE

\begin{tabular}{|c|c|c|c|c|c|c|}
\hline $\mathbf{n}$ & Rmin & Rmax & pmin & pmax & tmin & tmax \\
\hline 5 & 1.75 & 2 & 0.95 & 1.1 & 0.44 & 0.44 \\
\hline 10 & 1.722 & 1.722 & 0.833 & 1 & 1.3 & 1.433 \\
\hline 15 & 1.8 & 2 & 0.8 & 0.9 & 0.5 & 0.5 \\
\hline 20 & 1.3 & 1.9 & 0.8 & 1 & 0.4 & 0.5 \\
\hline 25 & 0.854 & 2 & 0.8125 & 1.25 & 0.425 & 0.475 \\
\hline 30 & 1.267 & 1.957 & 0.733 & 1.172 & 0.427 & 0.5 \\
\hline 35 & 1.265 & 2 & 0.72 & 1.25 & 0.429 & 0.5 \\
\hline 40 & 1.23 & 2 & 0.73 & 1.25 & 0.423 & 0.5 \\
\hline 45 & 1.261 & 2 & 0.756 & 1.25 & 0.425 & 0.5 \\
\hline 50 & 1.286 & 2 & 0.729 & 1.25 & 0.426 & 0.5 \\
\hline 55 & 1.259 & 2 & 0.722 & 1.25 & 0.422 & 0.5 \\
\hline 60 & 1.216 & 2 & 0.716 & 1.25 & 0.424 & 0.5 \\
\hline 65 & 1.238 & 2 & 0.734 & 1.25 & 0.425 & 0.5 \\
\hline 70 & 1.239 & 2 & 0.717 & 1.25 & 0.426 & 0.5 \\
\hline
\end{tabular}

TABLE VII. COMPARISON BETWEEN DESIGN EXPERIMENTS AND MODEL OF NORRIS AND PARKER

\begin{tabular}{|c|c|c|c|c|c|c|}
\hline $\mathbf{n}$ & Rmin & Rmax & pmin & pmax & tmin & tmax \\
\hline 5 & 2 & 2 & 1.1 & 1.1 & 0.44 & 0.44 \\
\hline 10 & 1.305 & 1.305 & 1 & 1 & 0.3 & 0.3 \\
\hline 15 & 1.38 & 2 & 1.1 & 1.1 & 0.38 & 0.44 \\
\hline 20 & 1.276 & 2 & 0.776 & 1.21 & 0.31 & 0.5 \\
\hline 25 & 1.167 & 2 & 0.781 & 1.25 & 0.312 & 0.5 \\
\hline 30 & 1.224 & 1.914 & 0.784 & 1.25 & 0.303 & 0.458 \\
\hline 35 & 1.338 & 2 & 0.83 & 1.25 & 0.297 & 0.491 \\
\hline 40 & 1.167 & 2 & 0.788 & 1.25 & 0.3 & 0.5 \\
\hline 45 & 1.233 & 2 & 0.756 & 1.25 & 0.302 & 0.5 \\
\hline 50 & 1.158 & 2 & 0.749 & 1.25 & 0.298 & 0.5 \\
\hline 55 & 1.167 & 2 & 0.736 & 1.25 & 0.3 & 0.5 \\
\hline 60 & 1.174 & 2 & 0.754 & 1.25 & 0.297 & 0.5 \\
\hline 65 & 1.16 & 2 & 0.746 & 1.25 & 0.298 & 0.5 \\
\hline 70 & 1.167 & 2 & 0.739 & 1.25 & 0.3 & 0.5 \\
\hline
\end{tabular}

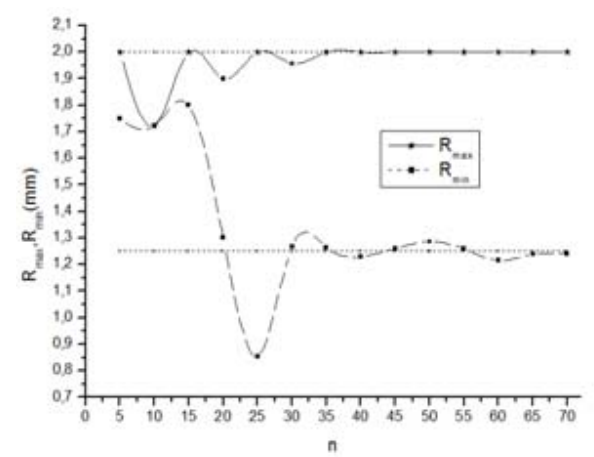

(a)

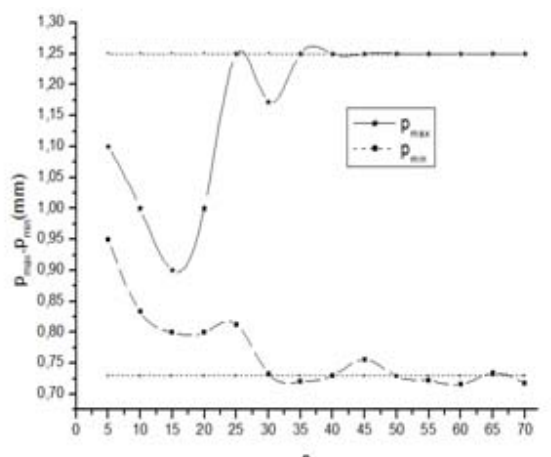

(b)

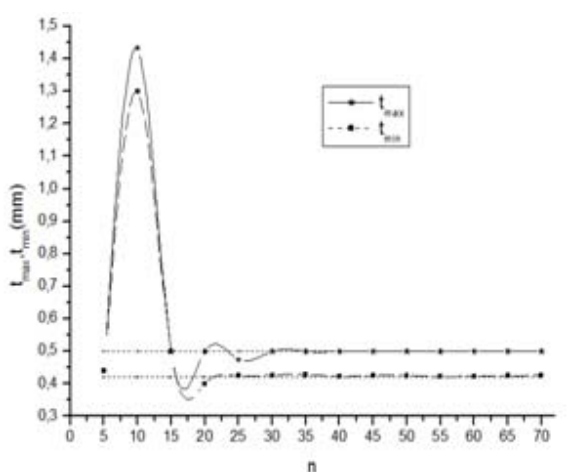

(c)

Fig. 4. Comparison of design of experiments and european code of practice (a) Rmax, Rmin vs n; (b) Pmax, Pmin vs n; (c) tmax, tmin vs n. 


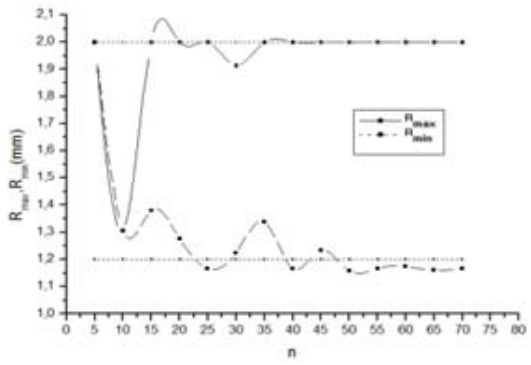

(a)

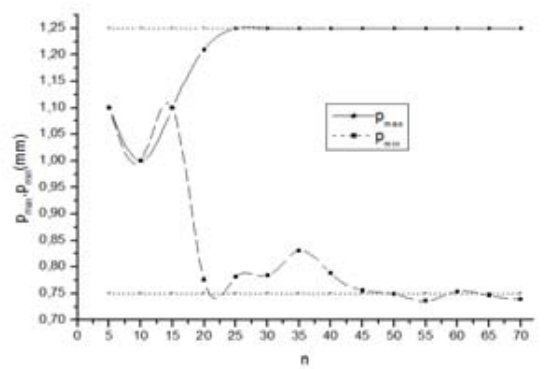

(b)

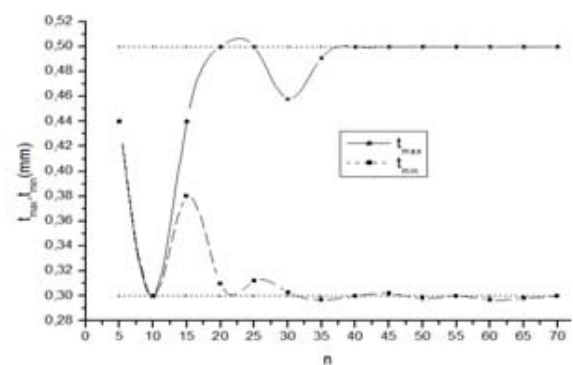

(c)

Fig. 5. comparison of design of experiments and norris and parker (a) $R_{\max }, R_{\min } v s n$; (b) $P_{\max } P_{\min } v s \mathrm{n}$; (c) $t_{\max }, t_{\min } v s n$.

\section{CONCLUSION}

This work has enabled the modeling of small punch test through an experimental approach combined with the development of a computer program, based on the comparison of the models obtained with two previous models that served as references. The permissible ranges of the variables $(\mathrm{R}, \mathrm{p}, \mathrm{t})$ proposed by the previous models were verified. A set of combinations of the variables $\mathrm{R}, \mathrm{p}, \mathrm{t}$ cited for numerous industrial application possibilities are given in Tables VIII and IX listed in the Annex.

\section{REFERENCES}

[1] G. E. Lucas, G. R. Odette, M. Sokolov, P. Spätig, T. Yamamoto, P. Jung, "Recent progress in small specimen test technology", Journal of Nuclear Materials, Vol. 307-311, pp. 1600-1608, 2002

[2] M. P. Manahan, A. E. Browning, A. S. Argon, O. K. Harling, "Miniaturised disk bend test technique development and application", In: The use of small scale specimen testing for irradiated material, (ed. W. R. Cronin and G. E. Lucas), STP 888, 17-49, Philadelphia, PA, ASTM, 1986

[3] J. R. Foulds, C. W. Jewett, R. Viswanathan, "Miniature specimen test technique for FATT", ASME International Power Generation Conference, San Diego, 1991

[4] J. M. Baik, J. Kameda, O. Buck, "Development of small punch tests for ductile-brittle transition temperature measurement of tempererature embrittled Ni-Cr steels", Proceedings of ASTM Symposium on The Use of Nonstandard Subsized Specimens for Irradiated Testing, New Mexico, 1983

[5] X. Mao, J. Kameda, "Small punch testing of measurement of material degradation of irradiated ferritic alloys", Journal of Materials Science, Vol. 26, No. 9, pp. 2436-2440, 1991

[6] J. Autillo, M. A. Contreras, C. Betegon, C. Rodrigez, F. J. Belzunce, "Utilizacion del ensayo miniatura de punzonamiento en la caracterizacion mecanica de aceros", Anales de Mecanica de la fractura, Vol. 23, pp. 77-83, 2006

[7] A. N. Sinclair, O. Lepik, M. Gabbani, B. Mukherjee, E. Albertini, "Assessment of fracture toughness by a punch test with miniature specimens". ASTM Syposium on Small Specimen Test Techniques and Their Applications to Nuclear Reactor Vessel Thermal Annealing and Plant Life Extension, ASTM STP1204, (W. R. Corvin, F. M. Haggag, W. L. Server eds), American Society for Testing and Materials, Philadelphia, pp. 162-181, 1993

[8] CEN Workshop Agreement CWA 15627, "Small punch test method for metallic materials (Part A)", European committee for standardization, 2006

[9] S. D. Norris, J. D. Parker, "Deformation processes during disc bend loading", Materials Science and Technology, Vol. 12, No. 2, pp. 163170,1996
[10] B. Ule, T. Sustar, F. Dobes, K. Milicka, V. Bicego, S. Tettamanti, K. Maile, C. Schwarzkopfd, M. P. Whelan, R. H. Kozlowski, J. Klaput, "Small punch test method assessment for the determination of the residual creep life of service exposed components: outcomes from an interlaboratory exercise", Nuclear Engineering and Design, Vol. 192, No. 1, pp. 1-11, 1999

[11] F. Dobes, K. Milicka, "On the Monkman-Grant relation for small punch test data", Materials Science and Engineering: A, Vol. 336, No. 1-2, pp. 245-248, 2002

[12] F. Dobes, K. Milicka, "Application of creep small punch testing in assessment of creep lifetime", Materials Science and Engineering: A, Vol. 510-511, pp. 440-443, 2009

[13] J. H. Bulloch, "Toughness losses in low alloy steels at high temperatures: an appraisal of certain factors concerning the small punch test”, International Journal of Pressure Vessels and Piping, Vol. 75, No. 11, pp. 791-804, 1998

[14] Y. Ma, Z. Horita, M. Furukawa, M. Nemoto, R. Z. Valiev, T. G. Langdon, "Yield stress measurements on an $\mathrm{Al}-1.5 \% \mathrm{Mg}$ alloy with submicron grain size using a miniature bending procedure", Materials Letters, Vol. 23, No. 4-6, pp. 283-287, 1995

[15] F. Hou, H. Xu, Y. Wang, L. Zhang, "Determination of creep property of $1.25 \mathrm{Cr} 0.5 \mathrm{Mo}$ pearlitic steels by small punch test", Engineering Failure Analysis, Vol. 28, pp. 215-221, 2013

[16] J. H. Bulloch, "A review of the ESB small punch test data on various plant components with special emphasis on fractographic details", Engineering Failure Analysis Vol. 9, No. 5, pp. 511-534, 2002

[17] G. E. Lucas, "Review of Small Specimen Test Techniques for Irradiation Testing”, Metallurgical Transactions A, Vol. 21, No. 5, 1990

[18] Z. Wang, H. Shi, J. Lu, P. Shi, X. Ma, "Small punch testing for assessing the fracture properties of the reactor vessel steel with different thicknesses", Nuclear Engineering and Design, Vol. 238, No. 12, pp. 3186-3193, 2008

[19] J. Goupy, L. Creighton, Introduction aux plans d'expériences, DUNOD, 2006

[20] M. Pillet, Les plans d'expérience par la méthode Taguchi, Editions d'Organisation, 2001

[21] O. Gaudoin, Principes et méthodes statistiques, Ensimag- 2ème Année, INP Grenoble, 2009 
TABLE VIII. COMBINATIONS OF TEST VARIABLES (PLAN OF EXPERIENCE / EUROPEAN CODE OF PRACTICE)

$\mathbf{R}$

$1.326923076923077 \mathrm{e}+000 \quad 8.269230769230769 \mathrm{e}-001$

$1.358974358974359 \mathrm{e}+000 \quad 8.846153846153846 \mathrm{e}-001$

$1.455128205128205 \mathrm{e}+000 \quad 8.461538461538462 \mathrm{e}-001$

$1.455128205128205 \mathrm{e}+000 \quad 9.038461538461539 \mathrm{e}-001$

$1.487179487179487 \mathrm{e}+000 \quad 7.692307692307692 \mathrm{e}-001$

$1.487179487179487 \mathrm{e}+000 \quad 1.038461538461538 \mathrm{e}+00$

$1.519230769230769 \mathrm{e}+000 \quad 8.076923076923077 \mathrm{e}-001$

$1.519230769230769 \mathrm{e}+000 \quad 9.615384615384616 \mathrm{e}-001$

$1.551282051282051 \mathrm{e}+000 \quad 8.846153846153846 \mathrm{e}-001$

$1.583333333333334 \mathrm{e}+000 \quad 9.807692307692308 \mathrm{e}-001$

$\begin{array}{ll}1.615384615384615 \mathrm{e}+000 & 7.500000000000000 \mathrm{e}-001\end{array}$

$1.615384615384615 \mathrm{e}+000 \quad 8.653846153846154 \mathrm{e}-001$

$1.647435897435897 \mathrm{e}+000$

$1.647435897435897 \mathrm{e}+000$

$1.679487179487180 \mathrm{e}+000$

$1.679487179487180 \mathrm{e}+000$

$1.711538461538462 \mathrm{e}+000$

$1.711538461538462 \mathrm{e}+000$

$1.711538461538462 \mathrm{e}+000$

$1.743589743589744 \mathrm{e}+000$

$1.807692307692308 \mathrm{e}+000$

$1.807692307692308 \mathrm{e}+000$

$1.839743589743590 \mathrm{e}+000$

$1.871794871794872 \mathrm{e}+000$

$1.903846153846154 \mathrm{e}+000$
$1.000000000000000 \mathrm{e}+000 \quad 4.307692307692308 \mathrm{e}-001$

$\begin{array}{ll}1.173076923076923 \mathrm{e}+000 & 4.384615384615385 \mathrm{e}-001\end{array}$

$1.019230769230769 \mathrm{e}+000 \quad 4.307692307692308 \mathrm{e}-001$

$1.096153846153846 \mathrm{e}+000 \quad 4.307692307692308 \mathrm{e}-001$

$1.038461538461538 \mathrm{e}+000 \quad 4.307692307692308 \mathrm{e}-001$

$1.057692307692308 \mathrm{e}+000 \quad 4.307692307692308 \mathrm{e}-001$

$1.153846153846154 \mathrm{e}+000 \quad 4.384615384615385 \mathrm{e}-001$

$1.192307692307692 \mathrm{e}+000 \quad 4.461538461538461 \mathrm{e}-001$

$1.134615384615385 \mathrm{e}+000 \quad 4.384615384615385 \mathrm{e}-001$

$1.211538461538462 \mathrm{e}+000 \quad 4.538461538461538 \mathrm{e}-001$

$1.173076923076923 \mathrm{e}+000 \quad 4.461538461538461 \mathrm{e}-001$

$1.230769230769231 \mathrm{e}+000 \quad 4.615384615384615 \mathrm{e}-001$

$1.250000000000000 \mathrm{e}+000 \quad 4.692307692307692 \mathrm{e}-001$ $\mathbf{p}+\mathbf{t}$

abs( R1-R2)

$4.464491361105827 \mathrm{e}-004$ $4.076666387792249 \mathrm{e}-004$ $4.714400510807959 \mathrm{e}-004$ $1.596450758211132 \mathrm{e}-004$ $3.588561039836735 \mathrm{e}-004$ $3.588561039836735 \mathrm{e}-004$
$4.558314209741621 \mathrm{e}-004$ $4.024617061731961 \mathrm{e}-004$ $3.143993290599667 \mathrm{e}-006$ $3.469995577822793 \mathrm{e}-004$ $3.927997191666144 \mathrm{e}-005$ 4.242916498056193e-004 $2.209377108854937 \mathrm{e}-004$ $4.173562455133117 \mathrm{e}-004$ $4.271211662808527 \mathrm{e}-004$ $1.129971355298132 \mathrm{e}-004$ $3.540596929840767 \mathrm{e}-004$ $4.455852458427057 \mathrm{e}-004$ $1.982211015507662 \mathrm{e}-004$ $4.047499885332373 \mathrm{e}-004$ $1.789344656100145 \mathrm{e}-004$ $1.563375008113432 \mathrm{e}-004$ $4.001535792800270 \mathrm{e}-004$ $4.849589176273428 \mathrm{e}-004$ $1.200892572432721 \mathrm{e}-004$ $4.290393902528500 \mathrm{e}-005$

TABLE IX. COMBINATIONS OF TEST VARIABLES (PLAN OF EXPERIENCE / MODEL NORRIS AND PARKER)

$1.262820512820513 \mathrm{e}+000$ $1.262820512820513 \mathrm{e}+000$ $1.423076923076923 \mathrm{e}+000$ $1.455128205128205 \mathrm{e}+000$ $1.455128205128205 \mathrm{e}+000$ $1.487179487179487 \mathrm{e}+000$ $1.551282051282051 \mathrm{e}+000$ $1.615384615384615 \mathrm{e}+000$ $1.615384615384615 \mathrm{e}+000$ $1.647435897435897 \mathrm{e}+000$ $1.679487179487180 \mathrm{e}+000$ $1.679487179487180 \mathrm{e}+000$ $1.679487179487180 \mathrm{e}+000$

$1.711538461538462 \mathrm{e}+000$

$1.743589743589744 \mathrm{e}+000$ $\mathbf{p}+\mathbf{t}$

9.038461538461539e-001 3.230769230769231e-001 $9.230769230769231 \mathrm{e}-001 \quad 3.153846153846154 \mathrm{e}-001$ $8.269230769230769 \mathrm{e}-001 \quad 4.461538461538461 \mathrm{e}-001$

$1.038461538461538 \mathrm{e}+000 \quad 3.153846153846154 \mathrm{e}-001$ $\begin{array}{ll}1.076923076923077 \mathrm{e}+000 & 3.076923076923077 \mathrm{e}-001\end{array}$

$1.115384615384615 \mathrm{e}+000 \quad 3.076923076923077 \mathrm{e}-001$

$1.134615384615385 \mathrm{e}+000 \quad 3.153846153846154 \mathrm{e}-001$ $\begin{array}{lll}1.153846153846154 \mathrm{e}+000 & 3.230769230769231 \mathrm{e}-001\end{array}$ $1.250000000000000 \mathrm{e}+000 \quad 3.230769230769231 \mathrm{e}-001$ $1.134615384615385 \mathrm{e}+000 \quad 3.307692307692308 \mathrm{e}-001$ $1.192307692307692 \mathrm{e}+000 \quad 3.307692307692308 \mathrm{e}-001$ $1.211538461538462 \mathrm{e}+000 \quad 3.307692307692308 \mathrm{e}-001$ $1.230769230769231 \mathrm{e}+000 \quad 3.307692307692308 \mathrm{e}-001$ $1.115384615384615 \mathrm{e}+000 \quad 3.461538461538462 \mathrm{e}-001$ $1.153846153846154 \mathrm{e}+000 \quad 3.461538461538462 \mathrm{e}-001$ $\mathbf{p}+\mathbf{t} \quad$ abs( R1-R2) $1.238461538461539 \mathrm{e}+000 \quad 4.085191353456752 \mathrm{e}-004$ $1.273076923076923 \mathrm{e}+000 \quad 1.508640411858053 \mathrm{e}-004$ $1.353846153846154 \mathrm{e}+000 \quad 8.555087374340076 \mathrm{e}-005$ $\begin{array}{lll}1.384615384615385 \mathrm{e}+000 & 4.378066387181745 \mathrm{e}-004\end{array}$ $1.423076923076923 \mathrm{e}+000 \quad 1.441483062560867 \mathrm{e}-004$ $1.450000000000000 \mathrm{e}+000 \quad 3.931497210469814 \mathrm{e}-004$ $1.476923076923077 \mathrm{e}+000 \quad 3.210561946248580 \mathrm{e}-004$ $1.573076923076923 \mathrm{e}+000 \quad 3.118853190887672 \mathrm{e}-004$ $1.465384615384615 \mathrm{e}+000 \quad 4.213653606355283 \mathrm{e}-005$ $1.523076923076923 \mathrm{e}+000 \quad 4.685962219056483 \mathrm{e}-004$ $1.542307692307692 \mathrm{e}+000 \quad 6.442938899375861 \mathrm{e}-005$ $\begin{array}{lll}1.561538461538462 \mathrm{e}+000 & 2.718541483529569 \mathrm{e}-004\end{array}$ $1.461538461538462 \mathrm{e}+000 \quad 2.638983263698602 \mathrm{e}-004$ $1.500000000000000 \mathrm{e}+000 \quad 3.247063243844162 \mathrm{e}-004$ 